\title{
Inflammation Biomarkers as Predictors of Pulmonary Outcomes in Cardiac Surgical Patients
}

\author{
Nadera J. Sweiss, Ray Sawaqed, Kenneth V. Leeper, Heval M. Kelli, Timothy Niewold, \\ Omar M. Lattouf ${ }^{*}$ \\ Emory University School of Medicine, Atlanta, USA. \\ Email: *olattou@emory.edu
}

Received November $1^{\text {st }}, 2013$; revised December $1^{\text {st }}, 2013$; accepted December $10^{\text {th }}, 2013$

Copyright @ 2013 Nadera J. Sweiss et al. This is an open access article distributed under the Creative Commons Attribution License, which permits unrestricted use, distribution, and reproduction in any medium, provided the original work is properly cited. In accordance of the Creative Commons Attribution License all Copyrights (C) 2013 are reserved for SCIRP and the owner of the intellectual property Nadera J. Sweiss et al. All Copyright (c) 2013 are guarded by law and by SCIRP as a guardian.

\begin{abstract}
Prolonged ventilator support, pulmonary infections and the need for tracheostomies after cardiac operations are associated with increased hospital mortality, length of stay, cost of hospitalization and reduced long term survival. The objective of this study is to review the literature and develop and present an understanding of the potential role of specific pre-operatively or intra-operatively collected inflammatory biomarkers and their role as predictors of pulmonary outcomes in cardiac surgery.
\end{abstract}

Keywords: CABG; COPD; Biomarkers

\section{Introduction}

Coronary artery bypass grafting (CABG) is the most common type of open heart surgery in the United States, with more than 175,000 individuals undergoing CABG in 2007 [1]. Most patients who undergo this surgery have one or more blockages in their coronary arteries as a result of atherosclerotic changes in the coronary circulation. CABG is performed to bypass these obstructions, which if left untreated would lead to ischemic heart disease and myocardial infarction. CABG was first used to revascularize patients with CAD in the 1960s and since has been used successfully on millions of patients worldwide providing sustained angina relief, increased exercise tolerance, less repeat revascularization and improved overall survival [2].

The complexity of performing the procedure and the associated complications from CABG have drastically decreased in recent years and accordingly the overall mortality rate following this surgery has been reduced to approximately 3\% [3]. Despite this overall morbidity and mortality reduction, the risk of postoperative pulmonary complications (PPCs) has remained stable [4]. Although the estimates regarding the incidence of postoperative

${ }^{*}$ Corresponding author. pulmonary complications (PPCs) vary widely, the consensus among several recent studies indicates that approximately one in every four to five people undergoing CABG may be affected by PPCs [5-8]. Atelectasis and pneumonia, are the leading causes of postoperative pulmonary complications [6,9], and, are believed to negatively impact the morbidity and mortality of the cardiac surgical patient.

A number of factors may contribute to the development of pulmonary complications following cardiac operations such as: diabetes mellitus, unstable angina, older age, female gender, moderate to severe renal insufficiency, a history of smoking, chronic obstructive pulmonary disease (COPD), and congestive heart failure (CHF) [9-11]. Multiple studies have shown that the use of the extra-corporeal circulation during cardiopulmonary bypass (CBP) contributes to systemic inflammatory reactions and may lead to unnecessary postoperative complications, including respiratory, neurologic, and cardiac dysfunction [12]. Despite the growing evidence that offpump coronary artery bypass (OPCABG) is shown to be associated with reduction of long term adverse outcome and various complications including PPC, patients undergoing on or off pump procedures still experience important postoperative complications [12]. Pro-inflam- 
matory biomarkers have been shown to influence the development of PPCs after major heart surgery. The aim of this review to describe the potential role of pro-inflammatory biomarkers in the cardiac surgical patients. In doing so, we first review the role of inflammation in CAD onset and describe the use of inflammatory biomarkers in predicting ischemic heart disease. We then describe advances in therapies that target cytokines and other pro-inflammatory mediators. We conclude this review by comparing on- and off-pump cardiac surgeries and how these techniques may influence PPCs in patients undergoing CABG.

\section{Inflammatory Processes in Coronary Artery Disease}

CAD affects 17.6 million American adults or nearly 8\% of the United States population [1]. It remains the leading cause of death in the US, causing nearly one out of every six deaths in 2006 [1]. CAD has a slow and insidious onset that often remains asymptomatic for years. Atherosclerotic plaques form gradually over years, narrowing the coronary arteries to the point of partial or total occlusion. Additionally, atherosclerotic plaques may become unstable and rupture, resulting in an acute myocardial ischemia or infarction. Treating CAD may involve pharmacological intervention, percutaneous intervention or surgical revascularization. The ultimate goals being to reduce symptoms of ischemia and to prevent MI and death [13]. Understanding the underlying mechanisms of atherogenesis and its eventual manifestations as ischemic heart disease has important preventative, diagnostic, and therapeutic relevance in CAD.

In recent years, a general appreciation for the role of systemic inflammation in the onset and evolution of atherosclerosis has spurred research on CAD risk factors that induce inflammatory reactions [14]. These proinflammatory risk factors (e.g., hyperlipidemia, hypertension, diabetes, obesity and smoking among others) trigger atherogenesis by damaging the vascular endothelium that lines blood vessels leading to impairment of endothelial cell function and the beginning of the atherosclerosic process. As endothelial cells become dysfunctional, resulting in atherosclerotic plaque formation, thickening of arterial walls, and eventually destabilization of plaques resulting in ischemic heart disease [13-16].

The vascular endothelium maintains homeostasis by producing nitric oxide, prostacyclin, and endothelin, which regulate vascular tone, coagulation, vascular inflammation and cell migration [14]. Endothelial cell mediator nitric oxide (NO), a strong vasodilatory and antithrombotic agent produced by endothelial nitric oxide synthase (eNOS ) in response to shear stress, plays an important role in blood flow dynamics in blood vessels [16]. When the vascular endothelium becomes impaired, an imbalance in homeostasis occurs, causing NO and prostacyclin levels to decrease and levels of endothelin-1 and other factors like angiotensin II, and plasminogen activator inhibitor-1 (PAI-1) to increase. These imbalances lead to an overall vascular shift away from endothelium-dependent vasodilatation toward vasoconstriction, thrombosis and proliferation $[13,17]$.

Hypercholesterolemia, a risk factor for progressive atherosclerosis [15-17], creates a fertile environment for oxidizing low-density lipoprotein (LDL) that concentrate inflammatory mediators (e.g., cytokines and cell adhesion molecules) to initiate plaque formation. Chemokines promote monocyte and immune cell recruitment to the endothelium, and leukocyte adhesion molecules facilitate the subsequent attachment of monocytes to activated endothelial cells, positioning them for transendothelial migration into the intima [15]. Once in the subendothelial space, monocytes differentiate into macrophages which ingest oxidized LDL molecules to form foam cells. These cells form the core of atherosclerotic plaques which are composed of inflammatory infiltrates and deposited lipid molecule resulting in vessel narrowing [13,14]. Plaques, characterized by extensive inflammation and a thin fibrous cap, are susceptible to ulceration, rupture, and thrombosis, which are the typical events underlying an acute coronary syndrome [18].

Within the arterial wall, macrophages also stimulate inflammation through a number of different mechanisms. Notably, they release interleukin-6 (IL-6), which induces downstream C-reactive protein (CRP) production by the liver. CRP is an established inflammatory mediator in atherosclerosis. The presence of CRP in the circulation stimulates macrophages to phagocytize LDL, thereby enhancing foam cell generation and plaque formation. CRP, reported to upregulate adhesion molecules in arterial endothelial cells [19], is associated with overall endothelial cell dysfunction [20], and may contribute directly to the inflammation which results in plaque instability and subsequent rupture [21].

Taken together, the inflammatory mechanisms implicated in CAD development may involve the proinflammatory cytokines, adhesion molecules, and other biomarkers of inflammation.

\section{Markers of Inflammation}

Inflammation, a major contributors to atherosclerosis and CAD pathogenesis, and markers of inflammation being potentially useful in predicting the course of CAD have led to the investigation of biomarkers as tools that could be used in diagnosing, prognosticating and managing CAD and many other conditions.

\subsection{White Blood Cells}

Obtaining white blood cell (WBC) counts is a potential 
first step in detecting systemic inflammation. Elevated levels of WBCs have been linked to an increased incidence of CAD and a higher risk of mortality from cardiovascular causes [22]. In particular, neutrophil levels have been found to independently correlate with adverse ischemic events in high-risk subsets of individuals with CAD [23]. Increased WBC counts have been associated with increased risk of future ischemic stroke, a related atherosclerotic condition [24].

\subsection{Macrophage Colony Stimulating Factor (MCSF)}

After an initial insult to the vascular endothelium (i.e., by increased LDL deposition), inflammatory mechanisms perpetuate atherosclerosis progression. For example, proinflammatory cytokines (e.g., macrophage colony stimulating factor (MCSF)) assist in activating macrophages, contributing to foam cell production and atherosclerotic plaque formation. Elevated levels of MCSF have been observed in both acute and chronic CAD, and high levels are associated with high risk of unstable angina, MI, and even death [25,26]. MCSF also stimulates the secretion of additional cytokines (e.g., IL-1b, IL-6, and monocyte chemoattractant protein-1 (MCP-1)), which help regulate macrophage activation, plaque formation, and CRP expression [19,27]. In addition to inducing cytokines production, MCSF also triggers the expression of monocyte chemoattractant protein-1 (MCP-1), which contributes to the processes of leukocyte adhesion and transendothelial migration, all of which play important roles in atherosclerosis and plaque formation.

\subsection{IL-6}

IL-6, which is produced and secreted by macrophages, endothelial cells and $\mathrm{T}$ lymphocytes, is measurably elevated in acute and chronic CAD [28]. IL-6 is also increased during muscle contraction and may play a role in insulin resistance [29]. It has been associated with autoimmune disorders, such as rheumatoid arthritis [30], which is itself an independent risk factor for CAD [31]. IL-6 plays a number of important roles in the immune system, including upregulation of CRP [32], but its role in predicting CAD onset and progression is still being evaluated. Intra-individual variation and short half life of IL-6 may limit the clinical utility of IL-6 measurement, and additional studies are needed to fully characterize its role as an inflammatory biomarker for CAD [29].

\subsection{C-Reactive Protein (CRP)}

CRP is currently used as a biomarker for CAD. While studies suggest that CRP plays a critical role in atherogenesis and CAD, it is still not completely clear whether the elevation of serum CRP that is observed is a cause or a result of the disease process. In support of the causal hypothesis, CRP has been reported to affect endothelial cells by decreasing eNOS levels and increasing the levels of inducible NOS (iNOS) [22]. Regardless, serum CRP measurements are an important predictor of CAD progression and adverse cardiovascular events. In a recent study, the predictive utility of CRP for CAD was investigated in a cohort of 6400 men and women without a history of MI from the Reykjavik Study [33]. Individuals who had the highest one-third of CRP levels within the cohort were reported to have a odds ratio of 1.45 for developing CAD relative to the bottom third of individuals (i.e., those with the lowest CRP levels) [33]. Notably, CRP also has been shown to predict long term survival independent of hyperlipidemia status and LDL levels [34]. However, it still remains to be determined how to optimally incorporate CRP levels in predictive models with conventional CAD risk factors (e.g., gender, age, and smoking status).

In the acute phase of atherosclerosis, levels of circulating CRP can increase several-thousand fold from baseline, a level easily detectable with the conventional CRP assay. However, the newer high-sensitivity CRP test allows for detection of small increases in CRP, which would be indicative of chronic low-grade inflammation [29]. Although the role for CRP as an inflammatory marker for CAD development and progression is emerging, it is possible that reduction in CRP level could predict decreased incidence or severity of CAD, in which case monitoring changes in CRP levels due to medications and lifestyle changes may be important in CAD prevention.

\subsection{Lipoprotein-Associated Phospholipase A2 (Lp-PLA2)}

Lp-PLA $A_{2}$ is an enzyme that is produced by hematopoietic cells which is carried on LDL and is found in atherosclerotic lesions. Elevated serum levels of Lp-PLA $\mathrm{A}_{2}$ appear to be proinflammatory and may induce plaque destabilization and rupture [35]. Furthermore, Lp-PLA $\mathrm{A}_{2}$ is involved in hydrolyzing oxidized LDL phospholipids, thereby stimulating production of bioactive lipid mediators, which also may have proinflammatory actions [36]. With these lipid mediators, Lp-PLA $\mathrm{A}_{2}$ may participate in a positive feedback loop [29]. The bioactive lipid mediators produced in the arterial tissue recruit more LDL and inflammatory cells to the sites of atherosclerotic lesions, thereby inducing further plaque formation and more Lp-PLA $A_{2}$ expression resulting in a positive feedback loop [29].

Increased levels of Lp-PLA $\mathrm{A}_{2}$ have been linked to an increased risk of adverse cardiovascular events and coronary heart disease [37]. This association with cardiovascular events in individuals with CAD and is inde- 
pendent of other cardiovascular risk factors, including circulating levels of CRP [38]. A large ongoing study of approximately 15,000 patients with cardiovascular disease, the Lp-PLA 2 Studies Collaboration (LSC), is currently combining data from 32 prospective studies to further define the role of Lp-PLA ${ }_{2}$ in CAD [39]. This study should help determine whether Lp-PLA $A_{2}$ is a reliable biomarker for CAD development and progression.

\section{Inflammation Contributes to CAD and CABG Pathogenesis}

\subsection{COPD}

The World Health Organization defines COPD as an under-diagnosed, life-threatening lung disease characterized by chronic obstruction of lung airflow that interferes with normal breathing, which is not fully reversible [40]. It is now one of the leading causes of mortality and morbidity worldwide [40], and is a major contributor to increased cost of healthcare, repeat hospitalization, decreased quality of life, decreased respiratory function, increased cardiovascular events and increased mortality [41-43].

COPD is a common comorbidity in patients with CAD, affecting $18.6 \%$ of individuals undergoing CABG [32]. Comorbid COPD has been reported to adversely affect patient outcomes following CABG [44]. Cohen and colleagues found that patients with COPD undergoing CABG had longer ICU stays, longer intubation periods, more frequent reintubations, more postoperative atrial and ventricular arrhythmias and associated complications, and had an overall longer duration of hospital stays and intensive care unit stays. Additionally, these patients have a high postoperative mortality rate with postoperative arryhtimias being a major cause [44]. Given the risk of developing complications after undergoing CABG in COPD patients, those who are candidates for CABG should not be in exacerbation prior to the procedure.

\subsection{Inflammatory Processes in COPD and Other Pulmonary-Related Diseases}

COPD pathogenesis is characterized by an abnormal inflammatory response of the lungs to noxious particles. Acute exacerbation of COPD may occur secondary to exposure to pollutants, irritants [45] or cold weather. As in other inflammatory diseases, cytokines play a key role in orchestrating chronic inflammation. More than 50 cytokines have been implicated in COPD pathogenesis and progression, but their precise roles in its complex pathophysiology are still unclear $[46,47]$. The presence of systemic inflammation in patients with COPD has been suggested in several different studies [48-51]. In these studies, evidence of systemic inflammation includes the following: activated circulating neutrophils and lymphocytes, increased plasma levels of mediators such as
TNF- $\alpha$ and its receptors (IL-6, IL-8, endothelin-1, and CRP), and the expression of adhesion molecules and $G$ proteins in circulating neutrophils. Such underlying inflammation may be particularly important given the recognized association between raised systemic inflammatory markers and increased cardiovascular mortality [52], a common cause of death in patients with COPD [53].

Airway inflammatory markers levels are reported to increase with exacerbation of COPD [54], and an elevation in these markers may occur irrespective of the etiology of the illness (i.e., whether it is due to a viral, bacterial, or other agents). Respiratory viruses are likely to be responsible for a high proportion of COPD exacerbations, with between $33 \%$ and $50 \%$ of COPD exacerbations being linked to upper respiratory tract infection (URI) symptoms [54,55]. Rhinovirus (RV), a common culprit of URIs that may account for $60 \%$ of virus-induced asthmatic exacerbations [56], is known to trigger COPD exacerbations [57-59]. Despite the association between exacerbations of COPD and infections, it is not clear that all exacerbations are related to respiratory tract infections [60,61].

Similar to the inflammatory processes that involve coronary artery wall epithelial cells in CAD, human airway epithelial cells (HAECs) also release a array of cytokines and chemokines which regulate the intensity of mucosal inflammation [62]. For example, in pulmonary infections with respiratory viruses, the airway epithelium produces proinflammatory cytokines, chemokines, adhesion molecules, and TNF- $\alpha$ [63-67]. These inflammatory mediators contribute to a mechanism that underlies the pathogenesis of exacerbations of asthma and COPD [68] by a number of mechanisms. They promote the release of other proinflammatory/chemotactic mediators, up-regulate adhesion molecules, which stimulate eosinophil and neutrophil migration, and induce airway smooth muscle to become hypercontractile [67]. In turn, lung macrophages, the most abundant cells in the airway lumen, are recruited and become activated. As a result, they secrete a wide range of antiviral, proinflammatory and immunomodulatory cytokines [69].

IL-1b is an example of one such pro-inflammatory cytokine produced by HAECs that is thought to have an important role in the pathogenesis of asthma. IL-1b levels are increased in bronchoalveolar lavage fluid in asthma and these levels correlate with the activation of alveolar macrophages and $\mathrm{T}$ cells in addition to the severity of airway dysfunction [70]. IL-1b levels are increased in tracheobronchial epithelial cells in asthmatic as compared to normal subjects [71]. IL-8, another chemokine found in the nasal secretions and sputum of patients with RV-induced asthma exacerbations is believed to have a role in the pathogenesis of asthma and COPD exacerbations [59,72,73]. IL-8 levels are correlated with 
numbers of neutrophils present in pulmonary secretions [59,72,73]. Furthermore, during exacerbation of COPD, increased sputum levels of factors including IL-6, IL-8, and TNF- $\alpha$, are suggestive of an inflammatory burst $[54,74,75]$. Acute inflammatory response during acute COPD exacerbation leads to a significantly elevated levels of TNF- $\alpha$ and IL- 8 in the sputum of COPD patients compared with when they were clinically stable $(\mathrm{p}=0.01$ and $\mathrm{p}=0.05$, respectively). Such markers were noted to be elevated in patients with confirmed viral and bacterial infections. Concentrations of these cytokines declined significantly 1 month after the exacerbation [74].

Elevated inflammatory markers have also been detected in exhaled breath condensate of patients with COPD [76]. The increased levels of inflammatory cells, cytokines and/or chemokines in the lungs as well as their elevated levels in the plasma/serum of patients with COPD have led to the strong suggestion that the local inflammatory response is detectable in the systemic circulation [74,77-79]. Even patients with stable COPD may express inflammatory biomarkers. Some studies suggest that these biomarkers may be found in lower levels than those patients experiencing acute COPD exacerbations [80]. However, inter- and intra-patient variability in the relative levels of the biomarkers have been reported [81] and additional studies are needed to fully characterize the differences in biomarkers during stable COPD and COPD exacerbations.

\subsection{Targeting Cytokines to Treat Inflammatory Conditions}

In other chronic inflammatory diseases, such as rheumatoid arthritis (RA) and inflammatory bowel disease (IBD), blocking individual cytokines has been highly effective. For example, blocking TNF- $\alpha$ is effective in over $50 \%$ of patients with RA, and blocking IL- 6 or IL- 1 receptors in patients who do not respond to anti-TNF- $\alpha$ therapies may be an effective second line strategy [82]. Studies targeting specific cytokines in COPD with blocking antibodies have not been highly successful to date, however ongoing studies with newer agents currently are being investigated.

Canakinumab is a novel IL-1b antibody that is currently being evaluated for its utility in COPD. In addition, the IL-6 receptor antibody tocilizumab which has been used in studies of RA and IBD may be considered in COPD. Furthermore, studies of apilimod, a small molecule inhibitor of IL-12/IL-23 p40 receptors, are ongoing in several autoimmune diseases including IBD, and potentially COPD [83].

\section{Inflammation, CAD, Pulmonary Function, and the Cardiac Surgical Patient}

Given the role of inflammation in CAD and pulmonary diseases like COPD, it is important to recognize the potential effects of pulmonary comorbidities on cardiac surgical outcome. Importantly, CABG itself elicits inflammatory responses, which may further exacerbate PPCs, particularly in patients with CAD and COPD.

For decades, on-pump CABG has successfully treated $\mathrm{CAD}$, and increased overall survival in some patients [3,84]. Performing on-pump CABG is known to stimulate perioperative proinflammatory mediators [85,86], which may contribute to the development of PPCs as well as other complications including neurologic dysfunction [87,88], renal dysfunction [89], and infections [90]. Reasons for this CABG-induced proinflammatory state may be related to the exposure to the extracorporal circuits with all the associated tubing and foreign material $[85,86]$. The exposure of a patient's blood to surfaces outside the body may partially account for this inflammatory reaction [86]. In addition, CPB may cause atelectasis, which in turn, may cause macrophage activation and cytokine production [91,92]. As described throughout this review, cytokines, in turn, serve as inflammatory mediator by recruiting neutrophils to the lungs and further provoking the inflammatory response.

\section{Comment}

There are a number of causes that contribute to pulmonary dysfunction, and it is difficult to predict the degrees of PPCs that patients will experience after undergoing cardiac procedures. Namely, each of the following have been implicated in PPCs following cardiac surgery: 1) Compromised capillary endothelial integrity leading to leaky membranes and increased total lung water content and secondary pulmonary edema; 2) Altered pulmonary circulation vascular tone due to anesthetic agents, vasoactive agents used to support the cardiovascular function; 3) Factors which contribute to atelectasis such as cerebral and musculoskeletal effects leading to reduced mechanics of breathing; 4) Pain due to operative incisions and temporarily retained instrumentations i.e. chest tubes, and pain management i.e. use of narcotics, contribute to reduced ventilator drive and pulmonary function; and finally; 5) Other factors such as pre-operative de-conditioning, obesity, phrenic nerve paresis or rare nerve injury may contribute to the post operative pulmonary dysfunction [93].

Individuals who do suffer from pulmonary dysfunction due to causes mentioned above will require higher oxygen concentrations in order to maintain appropriate oxygen tension in their arteries. To avoid these complications and prevent surgical-related morbidity, every effort should be made preoperatively to identify patients at risk of developing PPCs. Individuals with restrictive pulmonary disease due to pulmonary venous congestion, large pleural effusions, and cardiomegaly causing lung com- 
pression and reduced pulmonary compliance may be at particularly high risk of developing PPCs. Restrictive lung disease as found in patients with interstitial lung disease, pulmonary fibrosis, sarcoidosis, pneumoconiosis, and collagen vascular diseases are also at risk of developing PPC after surgery $[94,95]$. Therefore, these individuals should be carefully evaluated prior to undergoing invasive procedures. Pre-operative identification of patients who are at risk of developing PPCs or other surgical-related complications is a necessary and important step in patient management. It is possible that in the future, inflammatory biomarkers could be used to identify patients at high risk of pulmonary complication prior to surgery, or possibly those at increased risk in the immediate post-op period. Such data would help to guide appropriate pre-operative measures to improve pulmonary function by using appropriate anti-biotic therapy if indicated, or by using pre-operative pulmonary bronchodilators, pulmonary exercises, cessation of smoking, preoperative incentive spirometry, deep-breathing exercises, and chest physiotherapy. Such pre-operative strategies often enable patients with obstructive pulmonary disease to undergo safe cardiac surgery [95], which would clearly benefit patients and improve overall surgical outcomes.

\section{REFERENCES}

[1] D. Lloyd-Jones, R. J. Adams, T. M. Brown, M. Carnethon, S. Dai, et al., "Heart Disease and Stroke Statistics-2010 Update: A Report from the American Heart Association," Circulation, Vol. 121, 2010, pp. e46-e215. http://dx.doi.org/10.1161/CIRCULATIONAHA.109.1926 $\underline{67}$

[2] K. A. Eagle, R. A. Guyton, R. Davidoff, F. H. Edwards, G. A. Ewy, et al., "ACC/AHA 2004 Guideline Update for Coronary Artery Bypass Graft Surgery: A Report of the American College of Cardiology/American Heart Association Task Force on Practice Guidelines (Committee to Update the 1999 Guidelines for Coronary Artery Bypass Graft Surgery)," Circulation, Vol. 110, No. 14, 2004, pp. e340-e437.

http://dx.doi.org/10.1161/01.CIR.0000138790.14877.7D

[3] T. B. Ferguson Jr., B. G. Hammill, E. D. Peterson, E. R. DeLong and F. L. Grover, "A Decade of Change-Risk Profiles and Outcomes for Isolated Coronary Artery Bypass Grafting Procedures, 1990-1999: A Report from the STS National Database Committee and the Duke Clinical Research Institute. Society of Thoracic Surgeons," The Annals of Thoracic Surgery, Vol. 73, No. 2, 2002, pp. 480489. http://dx.doi.org/10.1016/S0003-4975(01)03339-2

[4] P. K. Henke, "Improving Quality of Care in Vascular Surgery: The Tools Are Available Now," The American Journal of Surgery, Vol. 190, No. 2, 2005, pp. 333-337. http://dx.doi.org/10.1016/j.amjsurg.2005.05.036

[5] E. H. Hulzebos, P. J. Helders, N. J. Favie, R. A. De Bie, A. B. de la Riviere, et al., "Preoperative Intensive Inspi- ratory Muscle Training to Prevent Postoperative Pulmonary Complications in High-Risk Patients Undergoing CABG Surgery: A Randomized Clinical Trial,” JAMA, Vol. 296, No. 15, 2006, pp. 1851-1857.

http://dx.doi.org/10.1001/jama.296.15.1851

[6] L. Jensen and L. Yang, "Risk Factors for Postoperative Pulmonary Complications in Coronary Artery Bypass Graft Surgery Patients,” European Journal of Cardiovascular Nursing, Vol. 6, No. 3, 2007, pp. 241-246. http://dx.doi.org/10.1016/j.ejcnurse.2006.11.001

[7] S. C. Murthy, A. C. Arroliga, P. A. Walts, J. Feng, J. P. Yared, et al., "Ventilatory Dependency after Cardiovascular Surgery," The Journal of Thoracic and Cardiovascular Surgery, Vol. 134, No. 2, 2007, pp. 484-490. http://dx.doi.org/10.1016/j.jtcvs.2007.03.006

[8] I. Yanez-Brage, S. Pita-Fernandez, A. Juffe-Stein, U. Martinez-Gonzalez, S. Pertega-Diaz, et al., "Respiratory Physiotherapy and Incidence of Pulmonary Complications in Off-Pump Coronary Artery Bypass Graft Surgery: An Observational Follow-Up Study," BMC Pulmonary Medicine, Vol. 9, 2009, p. 36.

http://dx.doi.org/10.1186/1471-2466-9-36

[9] J. F. Legare, G. M. Hirsch, K. J. Buth, C. MacDougall and J. A. Sullivan, "Preoperative Prediction of Prolonged Mechanical Ventilation Following Coronary Artery Bypass Grafting,” European Journal Cardio-Thoracic Surgery, Vol. 20, No. 5, 2001, pp. 930-936. http://dx.doi.org/10.1016/S1010-7940(01)00940-X

[10] T. D. Keenan, Y. Abu-Omar and D. P. Taggart, "Bypassing the Pump: Changing Practices in Coronary Artery Surgery," Chest, Vol. 128, 2005, pp. 363-369. http://dx.doi.org/10.1378/chest.128.1.363

[11] T. J. Ryan, "Present-Day PTCR versus CABG: A Randomized Comparison with a Different Focus and a New Result," Journal of the American College of Cardiology, Vol. 37, No. 1, 2001, pp. 59-62. http://dx.doi.org/10.1016/S0735-1097(00)01051-2

[12] A. L. Shroyer, F. L. Grover, B. Hattler, J. F. Collins, G. O. McDonald, et al., "On-Pump versus Off-Pump CoronaryArtery Bypass Surgery," The New England Journal of Medicine, Vol. 361, No. 19, 2009, pp. 1827-1837. http://dx.doi.org/10.1056/NEJMoa0902905

[13] M. Drakopoulou, K. Toutouzas, E. Stefanadi, E. Tsiamis, D. Tousoulis, et al., "Association of Inflammatory Markers with Angiographic Severity and Extent of Coronary Artery Disease,” Atherosclerosis, Vol. 206, No. 2, 2009 , pp. 335-339.

http://dx.doi.org/10.1016/j.atherosclerosis.2009.01.041

[14] D. Tousoulis, M. Charakida and C. Stefanadis, "Endothelial Function and Inflammation in Coronary Artery Disease," Postgraduate Medical Journal, Vol. 84, No. 993, 2008, pp. 368-371.

http://dx.doi.org/10.1136/hrt.2005.066936

[15] P. Libby, P. M. Ridker and G. K. Hansson, "Inflammation in Atherosclerosis: From Pathophysiology to Practice," Journal of the American College of Cardiology, Vol. 54, No. 23, 2009, pp. 2129-2138. http://dx.doi.org/10.1016/j.jacc.2009.09.009

[16] M. A. Gonzalez and A. P. Selwyn, "Endothelial Function, 
Inflammation, and Prognosis in Cardiovascular Disease," American Journal of Medicine, Vol. 115, Suppl. 8A, 2003, pp. 99S-106S.

http://dx.doi.org/10.1016/j.amjmed.2003.09.016

[17] D. Behrendt and P. Ganz, "Endothelial Function. From Vascular Biology to Clinical Applications," American Journal of Cardiology, Vol. 90, No. 10, 2002, pp. 40L-48L. http://dx.doi.org/10.1016/S0002-9149(02)02963-6

[18] J. H. O’Keefe, M. D. Carter and C. J. Lavie, "Primary and Secondary Prevention of Cardiovascular Diseases: A Practical Evidence-Based Approach,” Mayo Clinic Proceedings, Vol. 84, No. 8, 2009, pp. 741-757. http://dx.doi.org/10.4065/84.8.741

[19] V. Pasceri, J. T. Willerson and E. T. Yeh, "Direct Proinflammatory Effect of C-Reactive Protein on Human Endothelial Cells," Circulation, Vol. 102, No. 18, 2000, pp. 2165-2168.

http://dx.doi.org/10.1161/01.CIR.102.18.2165

[20] S. Fichtlscherer, G. Rosenberger, D. H. Walter, S. Breuer, S. Dimmeler, et al., "Elevated C-Reactive Protein Levels and Impaired Endothelial Vasoreactivity in Patients with Coronary Artery Disease," Circulation, Vol. 102, No. 9, 2000, pp. 1000-1006. http://dx.doi.org/10.1161/01.CIR.102.9.1000

[21] A. Tanaka, K. Shimada, T. Sano, M. Namba, T. Sakamoto, et al., "Multiple Plaque Rupture and C-Reactive Protein in Acute Myocardial Infarction," Journal of the American College of Cardiology, Vol. 45, No. 10, 2005, pp. 1594-1599.

http://dx.doi.org/10.1016/j.jacc.2005.01.053

[22] I. Ikonomidis, C. A. Michalakeas, J. Lekakis, I. Paraskevaidis and D. T. Kremastinos, "Multimarker Approach in Cardiovascular Risk Prediction," Disease Markers, Vol. 26, No. 5-6, 2009, pp. 273-285. http://dx.doi.org/10.1155/2009/135423

[23] A. J. Grau, A. W. Boddy, D. A. Dukovic, F. Buggle, C. Lichy, et al., "Leukocyte Count as an Independent Predictor of Recurrent Ischemic Events,” Stroke, Vol. 35, No. 5, 2004, pp. 1147-1152. http://dx.doi.org/10.1161/01.STR.0000124122.71702.64

[24] M. S. Elkind, R. R. Sciacca, B. Boden-Albala, T. Rundek, M. C. Paik, et al., "Relative Elevation in Baseline Leukocyte Count Predicts First Cerebral Infarction,” Neurology, Vol. 64, No. 12, 2005, pp. 2121-2125. http://dx.doi.org/10.1212/01.WNL.0000165989.12122.49

[25] I. Ikonomidis, J. Lekakis, I. Revela, F. Andreotti and P. Nihoyannopoulos, "Increased Circulating C-Reactive Protein and Macrophage-Colony Stimulating Factor Are Complementary Predictors of Long-Term Outcome in Patients with Chronic Coronary Artery Disease,” European Heart Journal, Vol. 26, No. 16, 2005, pp. 1618-1624. http://dx.doi.org/10.1093/eurheartj/ehi192

[26] I. Ikonomidis, F. Andreotti and P. Nihoyannopoulos, "Reduction of Daily Life Ischaemia by Aspirin in Patients with Angina: Underlying Link between Thromboxane A2 and Macrophage Colony Stimulating Factor," Heart, Vol. 90, No. 4, 2004, pp. 389-393. http://dx.doi.org/10.1136/hrt.2003.015164

[27] R. Bataille and B. Klein, “C-Reactive Protein Levels as a
Direct Indicator of Interleukin-6 Levels in Humans in Vivo," Arthritis \& Rheumatism, Vol. 35, No. 8, 1992, pp. 982-984. http://dx.doi.org/10.1002/art.1780350824

[28] M. Y. Abeywardena, W. R. Leifert, K. E. Warnes, J. N. Varghese and R. J. Head, "Cardiovascular Biology of Interleukin-6,” Current Pharmaceutical Design, Vol. 15, No. 15, 2009, pp. 1809-1821. http://dx.doi.org/10.2174/138161209788186290

[29] N. Sarwar, A. J. Thompson and E. Di Angelantonio, "Markers of Inflammation and Risk of Coronary Heart Disease," Disease Markers, Vol. 26, No. 5-6, 2009, pp. 217-225. http://dx.doi.org/10.1155/2009/851962

[30] N. Nishimoto, "Interleukin-6 in Rheumatoid Arthritis," Current Opinion in Rheumatology, Vol. 18, No. 3, 2006, pp. 277-281.

http://dx.doi.org/10.1097/01.bor.0000218949.19860.d1

[31] K. J. Warrington, P. D. Kent, R. L. Frye, J. F. Lymp, S. L. Kopecky, et al., "Rheumatoid Arthritis Is an Independent Risk Factor for Multi-Vessel Coronary Artery Disease: A Case Control Study," Arthritis Research \& Therapy, Vol. 7, No. 5, 2005, pp. R984-R991. http://dx.doi.org/10.1186/ar1775

[32] D. Scrutinio and P. Giannuzzi, "Comorbidity in Patients Undergoing Coronary Artery Bypass Graft Surgery: Impact on Outcome and Implications for Cardiac Rehabilitation," European Journal of Cardiovascular Prevention and Rehabilitation, Vol. 15, No. 4, 2008, pp. 379-385. http://dx.doi.org/10.1097/HJR.0b013e3282fd5c6f

[33] J. Danesh, J. G. Wheeler, G. M. Hirschfield, S. Eda, G. Eiriksdottir, et al., "C-Reactive Protein and Other Circulating Markers of Inflammation in the Prediction of Coronary Heart Disease," The New England Journal of Medicine, Vol. 350, No. 14, 2004, pp. 1387-1397. http://dx.doi.org/10.1056/NEJMoa032804

[34] S. E. Nissen, E. M. Tuzcu, P. Schoenhagen, T. Crowe, W. J. Sasiela, et al., "Statin Therapy, LDL Cholesterol, CReactive Protein, and Coronary Artery Disease,” The New England Journal of Medicine, Vol. 352, No. 1, 2005, pp. 29-38. http://dx.doi.org/10.1056/NEJMoa042000

[35] D. M. Stafforini, "Biology of Platelet-Activating Factor Acetylhydrolase (PAF-AH, Lipoprotein Associated Phospholipase A2)," Cardiovascular Drugs and Therapy, Vol. 23, No. 1, 2009, pp. 73-83. http://dx.doi.org/10.1007/s10557-008-6133-8

[36] A. Zalewski and C. Macphee, "Role of Lipoprotein-Associated Phospholipase A2 in Atherosclerosis: Biology, Epidemiology, and Possible Therapeutic Target," Arteriosclerosis, Thrombosis, and Vascular Biology, Vol. 25, No. 5, 2005, pp. 923-931. http://dx.doi.org/10.1161/01.ATV.0000160551.21962.a7

[37] C. J. Packard, D. S. O’Reilly, M. J. Caslake, A. D. McMahon, I. Ford, J. Cooney, C. H. Macphee, K. E. Suckling, M. Krishna, F. E. Wilkinson, A. Rumley and G. D. Lowe, "Lipoprotein-Associated Phospholipase A2 as an Independent Predictor of Coronary Heart Disease," West of Scotland Coronary Prevention Study Group. New England Journal of Medicine, Vol. 343, No. 16, 2000, pp. 1148-1155.

http://dx.doi.org/10.1056/NEJM200010193431603 
[38] E. S. Brilakis, J. P. McConnell, R. J. Lennon, A. A. Elesber, J. G. Meyer and P. B. Berger, "Association of lipoprotein-Associated Phospholipase A2 Levels with Coronary Artery Disease Risk Factors, Angiographic Coronary Artery Disease, and Major Adverse Events at FollowUp,” European Heart Journal, Vol. 26, No. 2, 2005, pp. 137-144. http://dx.doi.org/10.1093/eurheartj/ehi010

[39] C. Ballantyne, M. Cushman, B. Psaty, C. Furberg, K. T. Khaw, et al., "Collaborative Meta-Analysis of Individual Participant Data from Observational Studies of Lp-PLA2 and Cardiovascular Diseases," European Journal of Preventive Cardiology, Vol. 14, No. 1, 2007, pp. 3-11. http://dx.doi.org/10.1097/01.hjr.0000239464.18509.f1

[40] R. A. Pauwels, A. S. Buist, P. M. Calverley, C. R. Jenkins and S. S. Hurd, "Global Strategy for the Diagnosis, Management, and Prevention of Chronic Obstructive Pulmonary Disease,” NHLBI/WHO Global Initiative for Chronic Obstructive Lung Disease (GOLD) Workshop Summary. American Journal of Respiratory and Critical Care Medicine, Vol. 163, No. 5, 2001, pp. 1256-1276. http://dx.doi.org/10.1164/ajrccm.163.5.2101039

[41] T. A. Seemungal, G. C. Donaldson, E. A. Paul, J. C. Bestall, D. J. Jeffries and J. A. Wedzicha, "Effect of Exacerbation on Quality of Life in Patients with Chronic Obstructive Pulmonary Disease," Journal of Respiratory and Critical Care Medicine, Vol. 157, No. 5, 1998, pp. 14181422. http://dx.doi.org/10.1164/ajrccm.157.5.9709032

[42] D. D. Sin and S. F. Man, "Why Are Patients with Chronic Obstructive Pulmonary Disease at Increased Risk of Cardiovascular Diseases? The Potential Role of Systemic Inflammation in Chronic Obstructive Pulmonary Disease,” Circulation, Vol. 107, No. 11, 2003, pp. 1514-1519. http://dx.doi.org/10.1161/01.CIR.0000056767.69054.B3

[43] S. D. Sullivan, S. D. Ramsey and T. A. Lee, "The Economic Burden of COPD,” Chest, Vol. 117, No. 2, 2000, pp. 5S-9S. http://dx.doi.org/10.1378/chest.117.2_suppl.5S

[44] A. Cohen, M. Katz, R. Katz, E. Hauptman and A. Schachner, "Chronic Obstructive Pulmonary Disease in Patients Undergoing Coronary Artery Bypass Grafting," The Journal of Thoracic and Cardiovascular Surgery, Vol. 109, No. 3, 1995, pp. 574-581. http://dx.doi.org/10.1016/S0022-5223(95)70291-1

[45] H. R. Anderson, C. Spix, S. Medina, J. P. Schouten, J. Castellsague, G. Rossi, D. Zmirou, G. Touloumi, B. Wojtyniak, A. Ponka, L. Bacharova, J. Schwartz and K. Katsouyanni, "Air Pollution and Daily Admissions for Chronic Obstructive Pulmonary Disease in 6 European Cities: Results from the APHEA Project," European Respiratory Journal, Vol. 10, No. 5, 1997, pp. 1064-1071. http://dx.doi.org/10.1183/09031936.97.10051064

[46] P. J. Barnes, "Mediators of Chronic Obstructive Pulmonary Disease," Pharmacological Reviews, Vol. 56, No. 4, 2004, pp. 515-548. http://dx.doi.org/10.1124/pr.56.4.2

[47] P. J. Barnes, "The Cytokine Network in Asthma and Chronic Obstructive Pulmonary Disease,” The Journal of Clinical Investigation, Vol. 118, No. 11, 2008, pp. 3546-3556. http://dx.doi.org/10.1172/JCI36130

[48] A. G. Agusti, A. Noguera, J. Sauleda, E. Sala, J. Pons and X. Busquets, "Systemic Effects of Chronic Obstructive Pul- monary Disease,” European Respiratory Journal, Vol. 21, No. 2, 2003, pp. 347-360.

http://dx.doi.org/10.1183/09031936.03.00405703

[49] A. A. Eid, A. A. Ionescu, L. S. Nixon, V. Lewis-Jenkins, S. B. Matthews, T. L. Griffiths and D. J. Shale, "Inflammatory Response and Body Composition in Chronic Obstructive Pulmonary Disease," American Journal of Respiratory and Critical Care Medicine, Vol. 164, No. 8, 2001, pp. 1414-1418.

http://dx.doi.org/10.1164/ajrccm.164.8.2008109

[50] M. Roland, A. Bhowmik, R. J. Sapsford, T. A. Seemungal, D. J. Jeffries, T. D. Warner and J. A. Wedzicha, "Sputum and Plasma Endothelin-1 Levels in Exacerbations of Chronic Obstructive Pulmonary Disease,” Thorax, Vol. 56, No. 1, 2001, pp. 30-35. http://dx.doi.org/10.1136/thorax.56.1.30

[51] J. H. Vernooy, M. Kucukaycan, J. A. Jacobs, N. H. Chavanes, W. A. Buurman, M. A. Dentener and E. F. Wouters, "Local and Systemic Inflammation in Patients with Chronic Obstructive Pulmonary Disease: Soluble Tumor Necrosis Factor Receptors Are Increased in Sputum," American Journal of Respiratory and Critical Care Medicine, Vol. 166, No. 9, 2002, pp. 1218-1224.

http://dx.doi.org/10.1164/rccm.2202023

[52] J. Danesh, R. Collins, P. Appleby and R. Peto, “Association of Fibrinogen, C-Reactive Protein, Albumin, or Leukocyte Count with Coronary Heart Disease: Meta-Analyses of Prospective Studies,” JAMA, Vol. 279, No. 18, 1998, pp. 1477-1482. http://dx.doi.org/10.1001/jama.279.18.1477

[53] A. L. Hansell, J. A. Walk and J. B. Soriano, "What do Chronic Obstructive Pulmonary Disease Patients Die from? A Multiple Cause Coding Analysis," European Respiratory Journal, Vol. 22, No. 5, 2003, pp. 809-814. http://dx.doi.org/10.1183/09031936.03.00031403

[54] A. Bhowmik, T. A. Seemungal, R. J. Sapsford and J. A. Wedzicha, "Relation of Sputum Inflammatory Markers to Symptoms and Lung Function Changes in COPD Exacerbations,” Thorax, Vol. 55, No. 2, 2000, pp. 114-120. http://dx.doi.org/10.1136/thorax.55.2.114

[55] T. A. Seemungal, G. C. Donaldson, A. Bhowmik, D. J. Jeffries and J. A. Wedzicha, "Time Course and Recovery of Exacerbations in Patients with Chronic Obstructive Pulmonary Disease," American Journal of Respiratory and Critical Care Medicine, Vol. 161, No. 5, 2000, pp. 16081613. http://dx.doi.org/10.1164/ajrccm.161.5.9908022

[56] S. L. Johnston, P. K. Pattemore, G. Sanderson, S. Smith, F. Lampe, et al., "Community Study of Role of Viral Infections in Exacerbations of Asthma in 9 - 11 Year Old Children,” British Medical Journal, Vol. 310, No. 6989, 1995, pp. 1225-1229. http://dx.doi.org/10.1136/bmj.310.6989.1225

[57] G. Rohde, A. Wiethege, I. Borg, M. Kauth, T. T. Bauer, A. Gillissen, A. Bufe and G. Schultze-Werninghaus, "Respiratory Viruses in Exacerbations of Chronic Obstructive Pulmonary Disease Requiring Hospitalisation: A CaseControl Study,” Thorax, Vol. 58, No. 1, 2003, pp. 37-42. http://dx.doi.org/10.1136/thorax.58.1.37

[58] T. Seemungal, R. Harper-Owen, A. Bhowmik, I. Moric, 
G. Sanderson, S. Message, P. Maccallum, T.W. Meade, D. J. Jeffries, S. L. Johnston and J. A. Wedzicha, "Respiratory Viruses, Symptoms, and Inflammatory Markers in Acute Exacerbations and Stable Chronic Obstructive Pulmonary Disease," American Journal of Respiratory and Critical Care Medicine, Vol. 164, No. 9, 2001, pp. 1618-1623. http://dx.doi.org/10.1164/ajrccm.164.9.2105011

[59] H. E. Fleming, F. F. Little, D. Schnurr, P. C. Avila, H. Wong, J. Liu, S. Yagi and H. A. Boushey, "Rhinovirus-16 Colds in Healthy and in Asthmatic Subjects: Similar Changes in Upper and Lower Airways," American Journal of Respiratory and Critical Care Medicine, Vol. 160, No. 1, 1999, pp. 100-108. http://dx.doi.org/10.1164/ajrccm.160.1.9808074

[60] I. Tager and F. E. Speizer, "Role of Infection in Chronic Bronchitis,” New England Journal of Medicine, Vol. 292, No. 11, 1975, pp. 563-571.

[61] D. W. Gump, C. A. Phillips, B. R. Forsyth, K. McIntosh, K. R. Lamborn and W. H. Stouch, "Role of Infection in Chronic Bronchitis," The American Review of Respiratory Disease, Vol. 113, No. 4, 1976, pp. 465-474.

[62] P. J. Barnes, K. F. Chung and C. P. Page, "Inflammatory Mediators of Asthma: An Update,” Pharmacological Reviews, Vol. 50, No. 4, 1998, pp. 515-596.

[63] P. H. Howarth, K. S. Babu, H. S. Arshad, L. Lau, M. Buckley, W. McConnell, P. Beckett, M. Al Ali, A. Chauhan, S. J. Wilson, A. Reynolds, D. E. Davies and S. T. Holgate, "Tumour Necrosis Factor (TNF $\alpha$ ) as a Novel Therapeutic Target in Symptomatic Corticosteroid Dependent Asthma,” Thorax, Vol. 60, No. 2, 2005, pp. 10121018. http://dx.doi.org/10.1136/thx.2005.045260

[64] V. M. Keatings, P. D. Collins, D. M. Scott and P. J. Barnes, "Differences in Interleukin-8 and Tumor Necrosis Factor-alpha in Induced Sputum from Patients with Chronic Obstructive Pulmonary Disease or Asthma,” American Journal of Respiratory and Critical Care Medicine, Vol. 153, No. 2, 1996, pp. 530-534.

http://dx.doi.org/10.1164/ajrccm.153.2.8564092

[65] A. Mantovani, S. Sozzani, M. Locati, P. Allavena and A. Sica, "Macrophage Polarization: Tumor-Associated Macrophages as a Paradigm for Polarized M2 Mononuclear Phagocytes,” Trends in Immunology, Vol. 23, No. 11, 2002, pp. 549-555. http://dx.doi.org/10.1016/S1471-4906(02)02302-5

[66] S. L. Johnston, A. Papi, P. J. Bates, J. G. Mastronarde, M. M. Monick and G. W. Hunninghake, "Low Grade Rhinovirus Infection Induces a Prolonged Release of IL-8 in Pulmonary Epithelium,” Journal of Immunology, Vol. 160, No. 12, 1998, pp. 6172-6181.

[67] P. S. Thomas, "Tumour Necrosis Factor- $\alpha$ : The Role of this Multifunctional Cytokine in Asthma,” Immunology and Cell Biology, Vol. 79, No. 2, 2001, pp. 132-140. http://dx.doi.org/10.1046/j.1440-1711.2001.00980.x

[68] J. Kidney, T. McManus and P. V. Coyle, "Exacerbations of Chronic Obstructive Pulmonary Disease,” Thorax, Vol. 57, No. 9, 2002, pp. 753-754. http://dx.doi.org/10.1136/thorax.57.9.753

[69] K. J. Tracey and A. Cerami, "Tumor Necrosis Factor, Other Cytokines and Disease," Annual Review of Cell Bi- ology, Vol. 9, 1993, pp. 317-343.

http://dx.doi.org/10.1146/annurev.cb.09.110193.001533

[70] D. H. Broide, M. Lotz, A. J. Cuomo, D. A. Coburn, E. C. Federman and S. I. Wasserman, "Cytokines in Symptomatic Asthma Airways," Journal of Allergy and Clinical Immunology, Vol. 89, No. 5, 1992, pp. 958-967. http://dx.doi.org/10.1016/0091-6749(92)90218-Q

[71] A. R. Sousa, S. J. Lane, J. A. Nakhosteen, T. H. Lee and R. N. Poston, "Expression of Interleukin-1 Beta (IL1Beta) and Interleukin-1 Receptor Antagonist (IL-1ra) on Asthmatic Bronchial Epithelium," American Journal of Respiratory and Critical Care Medicine, Vol. 154, No. 4, 1996, pp. 1061-1066.

http://dx.doi.org/10.1164/ajrccm.154.4.8887608

[72] J. E. Gern, R. Vrtis, K. A. Grindle, C. Swenson, W. W. Busse, "Relationship of Upper and Lower Airway Cytokines to Outcome of Experimental Rhinovirus Infection," American Journal of Respiratory and Critical Care Medicine, Vol. 162, No. 6, 2000, pp. 2226-2231. http://dx.doi.org/10.1164/ajrccm.162.6.2003019

[73] M. M. Pizzichini, E. Pizzichini, A. Efthimiadis, A. J. Chauhan, S. L. Johnston, P. Hussack, J. Mahony, J. Dolovich and F. E. Hargreave, "Asthma and Natural Colds. Inflammatory Indices in Induced Sputum: A Feasibility Study,” American Journal of Respiratory and Critical Care Medicine, Vol. 158, No. 4, 1998, pp. 1178-1184. http://dx.doi.org/10.1164/ajrccm.158.4.9712082

[74] S. D. Aaron, J. B. Angel, M. Lunau, K. Wright, C. Fex, N. le Saux and R. E. Dales, “Granulocyte Inflammatory Markers and Airway Infection During Acute Exacerbation of Chronic Obstructive Pulmonary Disease," American Journal of Respiratory and Critical Care Medicine, Vol. 163, No. 2, 2001, pp. 349-355. http://dx.doi.org/10.1164/ajrccm.163.2.2003122

[75] S. Gompertz, C. O’Brien, D. L. Bayley, S. L. Hill and R. A. Stockley, "Changes in Bronchial Inflammation During Acute Exacerbations of Chronic Bronchitis," European Respiratory Journal, Vol. 17, No. 6, 2001, pp. 1112-1119. http://dx.doi.org/10.1183/09031936.01.99114901

[76] S. A. Kharitonov and P. J. Barnes, "Exhaled Biomarkers,” Chest, Vol. 130, No. 5, 2006, pp. 1541-1546. http://dx.doi.org/10.1378/chest.130.5.1541

[77] V. M. Keatings and P. J. Barnes, “Granulocyte Activation Markers in Induced Sputum: Comparison between Chronic Obstructive Pulmonary Disease, Asthma, and Normal Subjects," American Journal of Respiratory and Critical Care Medicine, Vol. 155, No. 2, 1997, pp. 449-453. http://dx.doi.org/10.1164/ajrccm.155.2.9032177

[78] E. J. Oudijk, J. W. Lammers and L. Koenderman, “Systemic Inflammation in Chronic Obstructive Pulmonary Disease,” European Respiratory Journal, Vol. 22, No. 46, 2003, pp. 5s-13s. http://dx.doi.org/10.1183/09031936.03.00004603a

[79] A. Pesci, B. Balbi, M. Majori, G. Cacciani, S. Bertacco, P. Alciato and C. F. Donner, "Inflammatory Cells and Mediators in Bronchial Lavage of Patients with Chronic Obstructive Pulmonary Disease,” European Respiratory Journal, Vol. 12, No. 2, 1998, pp. 380-386. http://dx.doi.org/10.1183/09031936.98.12020380 
[80] G. Krommidas, K. Kostikas, G. Papatheodorou, A. Koutsokera, K. I. Gourgoulianis, C. Roussos, N. G. Koulouris and S. Loukides, "Plasma Leptin and Adiponectin in COPD Exacerbations: Associations with Inflammatory Biomarkers," Respiratory Medicine, Vol. 104, No. 1, 2010, pp. 4046. http://dx.doi.org/10.1016/j.rmed.2009.08.012

[81] E. Sapey, D. Bayley, A. Ahmad, P. Newbold, N. Snell and R. A. Stockley, "Inter-Relationships between Inflammatory Markers in Patients with Stable COPD with Bronchitis: Intra-Patient and Inter-Patient Variability,” Thorax, Vol. 63, No. 6, 2008, pp. 493-499. http://dx.doi.org/10.1136/thx.2007.086751

[82] M. Feldmann and S. R. Maini, "Role of Cytokines in Rheumatoid Arthritis: An Education in Pathophysiology and Therapeutics," Immunological Reviews, Vol. 223, No. 1, 2008, pp. 7-19. http://dx.doi.org/10.1111/j.1600-065X.2008.00626.x

[83] P. J. Barnes, "The Cytokine Network in Chronic Obstructive Pulmonary Disease,” American Journal of Respiratory Cell and Molecular Biology, Vol. 41, No. 6, 2009, pp. 631-638. http://dx.doi.org/10.1165/rcmb.2009-0220TR

[84] S. N. Hoffman, J. A. TenBrook, M. P. Wolf, J. B. Wong, S. G. Pauker and D. N. Salem, "A Meta-Analysis of Randomized Controlled Trials Comparing Coronary Artery Bypass Graft with Percutaneous Transluminal Coronary Angioplasty: One- to Eight-Year Outcomes," Journal of the American College of Cardiology, Vol. 41, No. 8, 2003, pp. 1293-1304.

http://dx.doi.org/10.1016/S0735-1097(03)00157-8

[85] J. C. Cleveland Jr., A. L. Shroyer, A. Y. Chen, E. Peterson and F. L. Grover, "Off-Pump Coronary Artery Bypass Grafting Decreases Risk-Adjusted Mortality and Morbidity,” The Annals of Thoracic Surgery, Vol. 72, No. 4, 2001, pp. 1282-1288. http://dx.doi.org/10.1016/S0003-4975(01)03006-5

[86] I. Deblier, A. M. Sadowska, A. Janssens, I. Rodrigus and W. A. DeBacker, "Markers of Inflammation and Oxidative Stress in Patients Undergoing CABG with CPB with and without Ventilation of the Lungs: A Pilot Study," Interactive CardioVasc Thoracic Surgery, Vol. 5, No. 4, 2006, pp. 387-391. http://dx.doi.org/10.1510/icvts.2006.128561

[87] G. H. Almassi, T. Sommers, T. E. Moritz, A. L. Shroyer, M. J. London, G. K. Sethi, F. L. Grover and K. E. Hammermeister, "Stroke in Cardiac Surgical Patients: Deter- minants and Outcome," The Annals of Thoracic Surgery, Vol. 68, No. 2, 1999, pp. 391-397. http://dx.doi.org/10.1016/S0003-4975(99)00537-8

[88] K. M. Taylor, "Central Nervous System Effects of Cardiopulmonary Bypass,” The Annals of Thoracic Surgery, Vol. 66, No. 5, 1998, pp. S20-S24.

[89] R. Ascione, C. T. Lloyd, M. J. Underwood, W. J. Gomes and G. D. Angelini, “On-Pump Versus Off-Pump Coronary Revascularization: Evaluation of Renal Function,” The Annals of Thoracic Surgery, Vol. 68, No. 2, 1999, pp. 493498. http://dx.doi.org/10.1016/S0003-4975(99)00566-4

[90] R. H. Jensen, M. Storgaard, R. Vedelsdal and N. Obel, "Impaired Neutrophil Chemotaxis after Cardiac Surgery," Scandinavian Cardiovascular Journal, Vol. 29, No. 3, 1995, pp. 115-118. http://dx.doi.org/10.3109/14017439509107216

[91] N. Kotani, H. Hashimoto, D. I. Sessler, M. Muraoka, J. S. Wang, M. F. O’Connor and A. Matsuki, "Neutrophil Number and Interleukin-8 and Elastase Concentrations in Bronchoalveolar Lavage Fluid Correlate with Decreased Arterial Oxygenation after Cardiopulmonary Bypass," Anesthesia \& Analgesia, Vol. 90, No. 5, 2000, pp. 10461051. http://dx.doi.org/10.1097/00000539-200005000-00009

[92] S. Tsuchida, D. Engelberts, V. Peltekova, N. Hopkins, H. Frndova, P. Babyn, C. McKerlie, M. Post, P. McLoughlin and B. P. Kavanagh, "Atelectasis Causes Alveolar Injury in Nonatelectatic Lung Regions," American Journal of Respiratory and Critical Care Medicine, Vol. 174, No. 3, 2006, pp. 279-289. http://dx.doi.org/10.1164/rccm.200506-10060C

[93] L. L. Liu and M. A. Gropper, "Respiratory and Hemodynamic Management after Cardiac Surgery," Current Treatment Options in Cardiovascular Medicine, Vol. 4, No. 2, 2002, pp. 161-169. http://dx.doi.org/10.1007/s11936-002-0036-y

[94] F. L. Grover, K. E. Hammermeister and C. Burchfiel, "Initial Report of the Veterans Administration Preoperative Risk Assessment Study for Cardiac Surgery,” The Annals of Thoracic Surgery, Vol. 50, No. 1, 1990, pp. 12-26.

[95] K. Kroenke, V. A. Lawrence, J. F. Theroux and M. R. Tuley, "Operative Risk in Patients with Severe Obstructive Pulmonary Disease,” JAMA, Vol. 152, No. 5, 1992, pp. 967-971.

http://dx.doi.org/10.1001/archinte.1992.00400170057011 